\title{
Effect of substrates and underlayer on CNT synthesis by plasma enhanced CVD
}

\author{
Liang Xu $\cdot$ Di Jiang $\cdot$ Yi-Feng Fu $\cdot$ Stephane Xavier $\cdot$ \\ Shailendra Bansropun • Afshin Ziaei • \\ Shan-Tung Tu $\cdot$ Johan Liu
}

Received: 15 August 2013/Accepted: 19 August 2013/Published online: 10 September 2013

(c) Shanghai University and Springer-Verlag Berlin Heidelberg 2013

\begin{abstract}
Due to their unique thermal, electronic and mechanical properties, carbon nanotubes (CNTs) have aroused various attentions of many researchers. Among all the techniques to fabricate CNTs, plasma enhanced chemical vapor deposition (PECVD) has been extensively developed as one growth technique to produce vertically-aligned carbon nanotubes (VACNTs). Though CNTs show a trend to be integrated into nanoelectromechanical system (NEMS), CNT growth still remains a mysterious technology. This paper attempts to reveal the effects of substrates and underlayers to CNT synthesis. We tried five different substrates by substituting intrinsic Si with high resistivity ones and by
\end{abstract}

L. Xu $\cdot$ S.-T. Tu

Division of Process Equipment Science and Engineering, School of Mechanical and Power Enigneering, East China University of Science and Technology, Shanghai 200237, People's Republic of China

L. Xu · D. Jiang $\cdot$ J. Liu $(\bowtie)$

BioNano Systems Laboratory, Department of Microtechnology and Nanoscience (MC2), Chalmers University of Technology, Göteborg, Sweden

e-mail: johan.liu@chalmers.se

Y.-F. Fu

SHT Smart High Tech AB, Göteborg, Sweden

S. Xavier · S. Bansropun · A. Ziaei

Thales Research and Technology, Palaiseau, France

J. Liu

Key Laboratory of New Displays and System Integration,

SMIT Center, and School of Mechatronics and Mechanical Engineering, Shanghai University, Shanghai 200072,

People's Republic of China increasing the thickness of $\mathrm{SiO}_{2}$ insulativity layer. And also, we demonstrated an innovative way of adjusting CNT density by changing the thickness of $\mathrm{Cu}$ underlayer.

Keywords Carbon nanotube (CNT) - Substrate · Underlayer · Effect

\section{Introduction}

Since the remarkable discovery work on CNTs in 1990s, this novel structure has stimulated extensive researches. CNTs have shown many promising characters, such as excellent thermal conductivity $[1,2]$, exceeding mechanical strength [3, 4], and unique electrical properties [5]. Due to these extraordinary properties, various related applications of CNTs have been boosted, such as composite materials [6, 7], logic and memory devices [8], switched capacitors [9], and membranes [10]. NEMS is one of the areas where CNTs are considered as a superior material for building various mechanical structures [11, 12].

Dipping into CNT research, substrates with different various kinds of catalysts have been tried to achieve better quality of CNTs. Despite the differences in preparations of substrates, $\mathrm{Fe}, \mathrm{Ni}, \mathrm{Co}[13]$ and $\mathrm{Cu}$ are the most frequently used catalysts for CNT growth. Different trials of various metal and oxide underlayers $[14,15]$ have been tested o find better growth results. In order to meet the requirement of future NEMS, it is inevitable to take well control of the CNT growth on different substrates and underlayers.

However, current researches of CNT growth on various substrates and underlayers are not very summarized. In this paper, several experiments were implemented to find out the effect of substrate type and underlayer thickness on CNT growth. 


\section{CNT growth on different substrates}

\subsection{Experiment details}

We designed a structure with $\mathrm{Ni}$ catalyst dots on TiN barrier pads, on various substrates, as shown in Fig. 1a. The diameter of Ni dots is around $800 \mathrm{~nm}$, while the TiN pads have a slightly larger diameter of $1.2 \mu \mathrm{m}$, in order to prevent potential diffusion of $\mathrm{Ni}$ into substrates. Magnified details are shown in Fig. 1 b.

Preparation of patterns on substrates was done by e-beam lithography. All the tested samples were all chip sized as $8 \mathrm{~mm} \times 8 \mathrm{~mm}$. All the growths were carried out by PECVD mode with the CNT CVD equipment-Black Magic, by Axitron. $\mathrm{NH}_{3}(300 \mathrm{sccm})$ and $\mathrm{C}_{2} \mathrm{H}_{2}(65 \mathrm{sccm})$ were chosen to be the feeding gases. After $15 \mathrm{~min}$ of growth at $650{ }^{\circ} \mathrm{C}$ with $650 \mathrm{~V}$ plasma voltage, samples were taken out for SEM observation.

\subsection{Results and discussion}

Silicon with native oxide of $2 \mathrm{~nm}$ thick is reported as the most commonly used growth substrate. Figure 2 shows the well grown CNT bumps on $\mathrm{Si} / 2 \mathrm{~nm} \mathrm{SiO}_{2}$ substrate with the TiN/Ni pattern structure shown in Fig. 1. On each

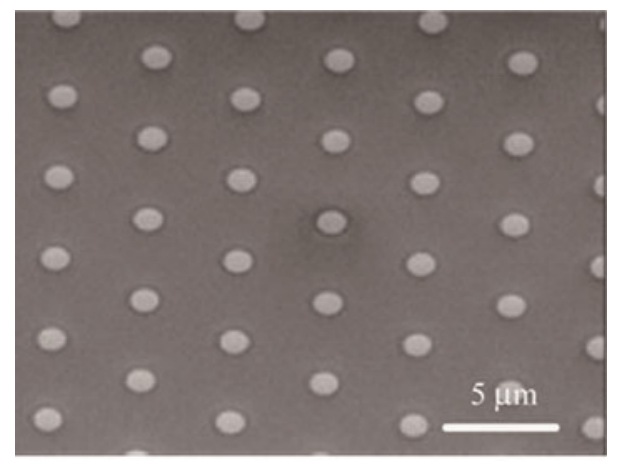

(a)

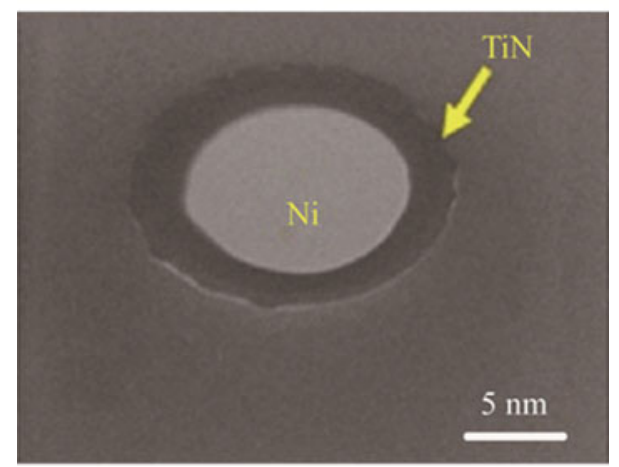

(b)

Fig. 1 Patterned structure design: a arrays of Ni catalyst dots with TiN barrier pads; $\mathbf{b}$ magnified view on one dot of Ni catalyst and TiN barrier pad patterned dot, CNTs are vertically aligned with similar length, reaching the height around $3 \mu \mathrm{m}$.

Among all the applications of CNTs, applying CNTs into NEMS switches for radio frequency (RF) field is a hot topic [16]. Due to the conducting property and parasitic capacitance of common $\mathrm{Si}$, which may lead to large signal losses and leakage especially in RF region [17], high resistivity $\mathrm{Si}(\mathrm{HR} \mathrm{Si}$ ) was chosen to improve the system performance [18].

Therefore, we tried substrates of $\mathrm{HR} \mathrm{Si} / 300 \mathrm{~nm} \mathrm{SiO}{ }_{2}$ and doped $\mathrm{Si} / 500 \mathrm{~nm} \mathrm{SiO}$. While undergoing the same growth period, what we got was totally different from the previous good result in Fig. 2. As Fig. 3 shown, CNT growths resulted poorly on both substrates. It's obvious that both substrates are totally damaged whose surfaces are no longer flat and continuous. What is more, if we take a closer look at the CNT morphology, the outlook of CNTs in Fig. 3 is hardly tube like, but actually like mountain shape. We suspected that this was caused by the damage of substrate surface decomposition and redeposition onto the protrusive CNTs' surface under high temperature and high plasma voltage.

To prevent the damage caused by plasma during growth, we tried another substrate of $\mathrm{HR} \mathrm{Si} / 2 \mu \mathrm{m} \mathrm{SiO}{ }_{2}$, with a thicker surface layer of $\mathrm{SiO}_{2}$ compared with that shown in Fig. 3a. As shown in Fig. 4a, although the surface of the substrate remained intact, the CNT growth is however not straight and falling down. We speculated that it was because of the low conductivity caused by the $2 \mu \mathrm{m}$ thick $\mathrm{SiO}_{2}$ surface. So we added another conductive layer of TiW on the substrate, which indicated the best CNT growth among all the substrates we tried in Fig. 4b. Though the lengths of CNTs are shorter compared with Fig. 2, it verifies the possibilities and feasibilities of integrating CNTs into NEMS in RF field.

\section{Effect of thickness of $\mathrm{Cu}$ underlayer on CNT growth density}

\subsection{Experiment details}

In this part, a set of experiments was carried out to study the effect of thickness of $\mathrm{Cu}$ underlayer. As shown in

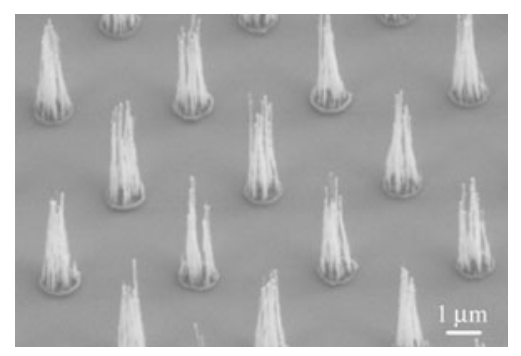

Fig. $2 \mathrm{CNT}$ growth results on $\mathrm{Si} / 2 \mathrm{~nm} \mathrm{SiO}_{2}$ substrate 


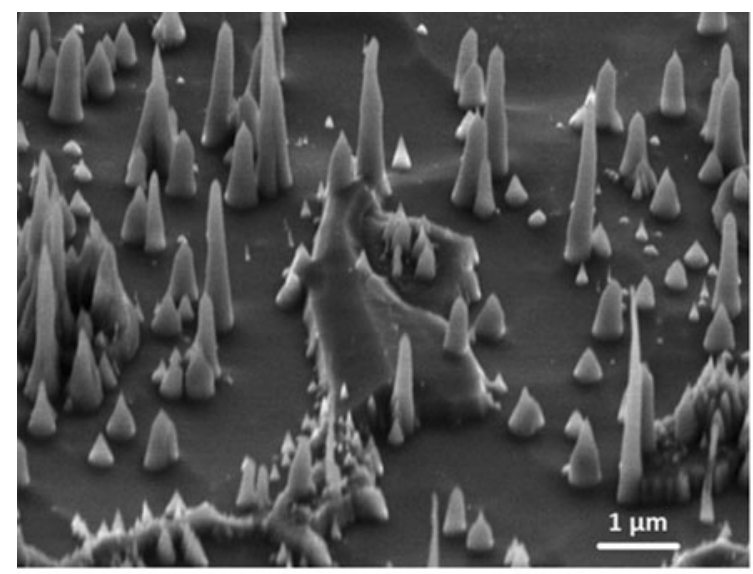

(a)

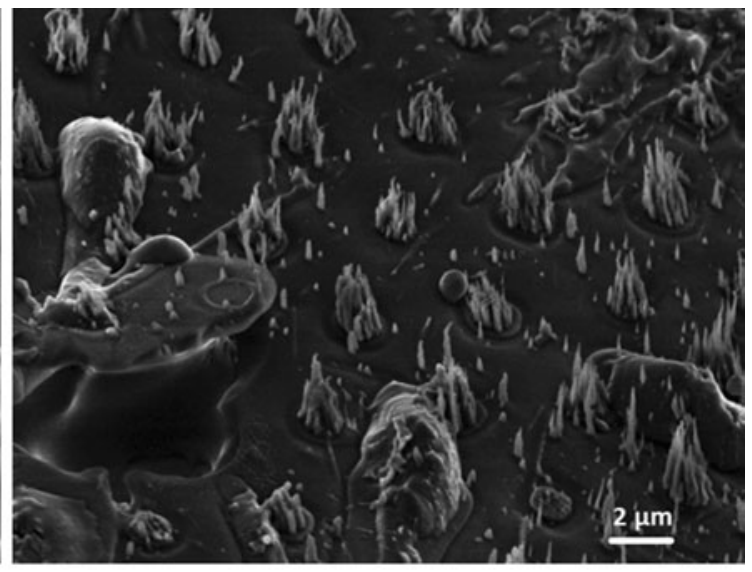

(b)

Fig. 3 a CNT growth results on $\mathrm{HR} \mathrm{Si/300} \mathrm{nm} \mathrm{SiO}{ }_{2}$ substrate; b CNT growth results on doped $\mathrm{Si} / 500 \mathrm{~nm} \mathrm{SiO}_{2}$ substrate

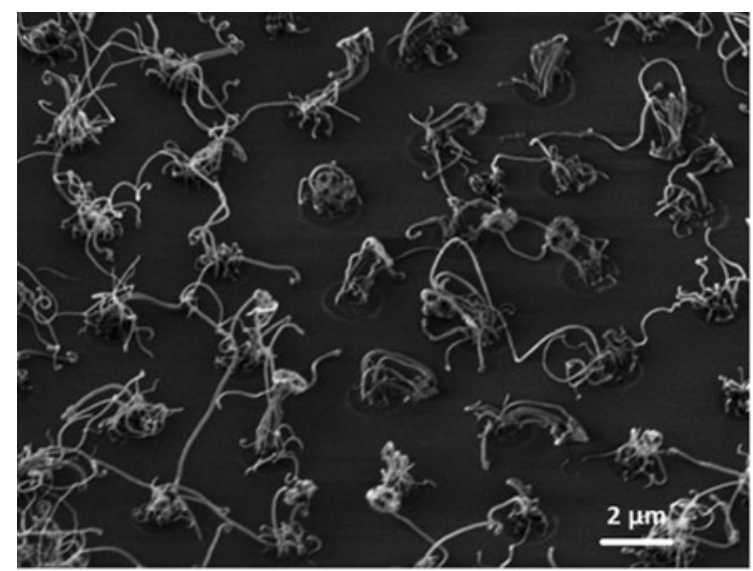

(a)

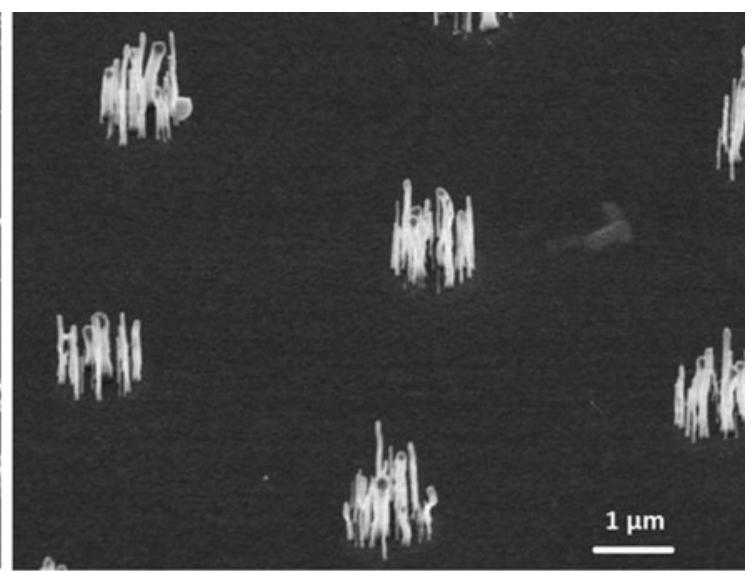

(b)

Fig. 4 a CNT growth results on $\mathrm{HR} \mathrm{Si} / 2 \mu \mathrm{m} \mathrm{SiO} 2$ substrate; b CNT growth results on $\mathrm{HR} \mathrm{Si} / 2 \mu \mathrm{m} \mathrm{SiO} 2 / 50 \mathrm{~nm} \mathrm{TiW}$ substrate

Fig. 5, we used $\mathrm{Cu}$ as underlayer, $\mathrm{Al}_{2} \mathrm{O}_{3}$ as barrier layer and $\mathrm{Ni}$ as catalyst. The only controlled parameter was the thickness of $\mathrm{Cu}$, ranging from $5 \mathrm{~nm}, 20 \mathrm{~nm}$ to $150 \mathrm{~nm}$. $\mathrm{Ni}$ catalyst layer and $\mathrm{Al}_{2} \mathrm{O}_{3}$ barrier layer were all controlled to be a fixed thickness of $7 \mathrm{~nm}$ and $10 \mathrm{~nm}$ respectively.

Depositions of different layers were done by electron beam evaporation. All the tested samples were of $10 \mathrm{~mm} \times 10 \mathrm{~mm}$ in size. All the growths are carried in PECVD mode with the CNT CVD equipment, Black Magic, by Axitron. $\mathrm{NH}_{3}$ and $\mathrm{C}_{2} \mathrm{H}_{2}$ were chosen to be the feeding gases. After $15 \mathrm{~min}$ of growth at $700{ }^{\circ} \mathrm{C}$ with $600 \mathrm{~V}$ plasma voltage, SEM was then used to study the morphologies of CNTs on samples' surfaces. Based on the CNT growth results, two important things would be investigated in this work: (i) the compatibility of $\mathrm{Al}_{2} \mathrm{O}_{3}$ barrier layers with $\mathrm{Cu}$ underlayer, (ii) the influence of $\mathrm{Cu}$ 's thickness to CNT growth.

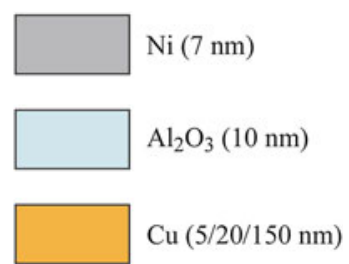

Fig. 5 Schematic diagram of experimental samples

\subsection{Results and discussion}

Figure 6 shows the CNT growth result with different thickness of $\mathrm{Cu}$ underlayer. As we expected, the growth of CNTs with $\mathrm{Al}_{2} \mathrm{O}_{3}$ barrier layer was acceptable. But here is an unexpected finding, with the increasing of the thickness of $\mathrm{Cu}$ underlayer, the quality and quantity of CNTs changes. In Fig. 6a, with $5 \mathrm{~nm}$ thick $\mathrm{Cu}$ underlayer, we can clearly see the root of each CNT indicating a low density of CNTs. At the same time, the CNTs are not so straight. In 


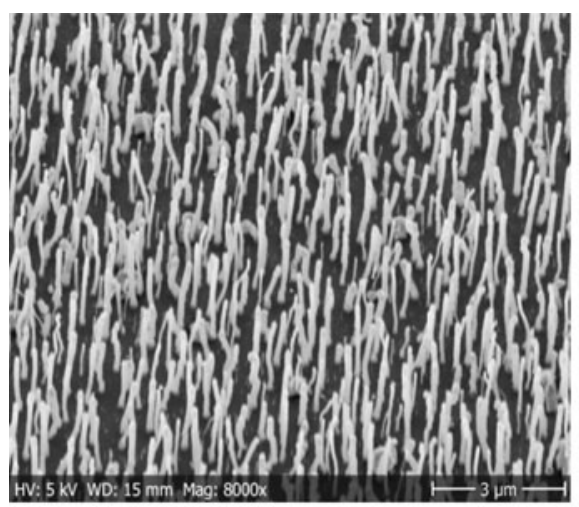

(a)

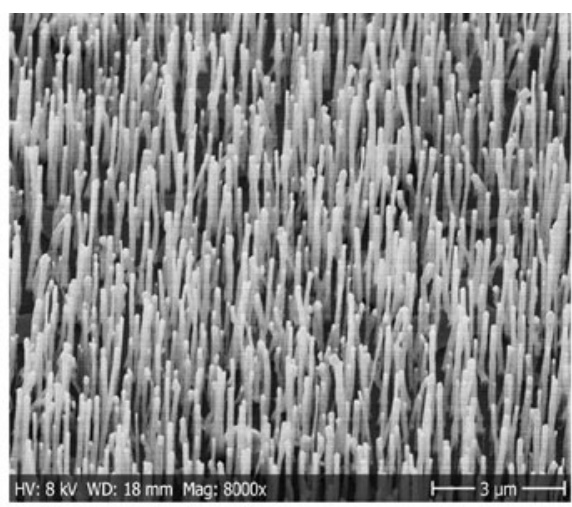

(b)

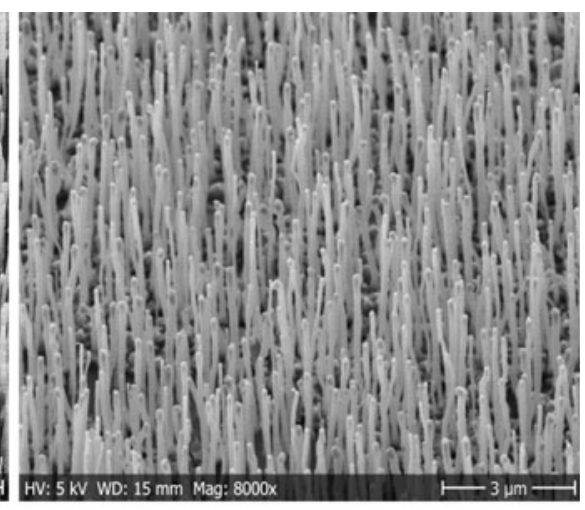

(c)

Fig. 6 SEM images of 3 samples with different Cu thickness: a $5 \mathrm{~nm}$ thick $\mathrm{Cu}$ underlayer; b $20 \mathrm{~nm}$ thick $\mathrm{Cu}$ underlayer; c $150 \mathrm{~nm}$ thick $\mathrm{Cu}$ underlayer

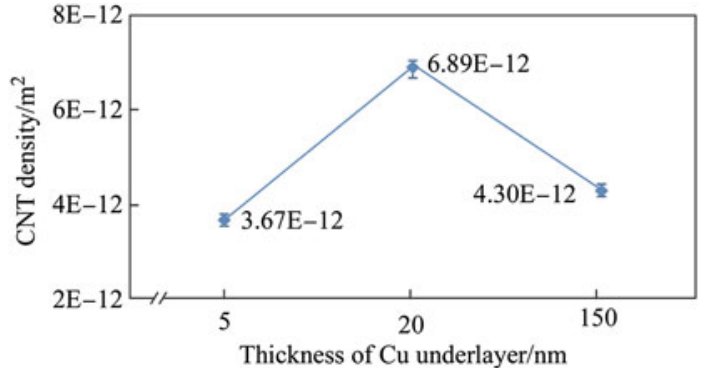

Fig. 7 Statistics of CNT number per meter square according to the average density of tested samples

Fig. 6b, with $20 \mathrm{~nm}$ thick $\mathrm{Cu}$ underlayer, the density of CNTs is larger than that in Fig. 6a, and the CNTs are straighter. Compared with Fig. 6b, Fig. 6c shows CNTs are less with curly tips. By watching carefully into the gaps between CNT roots, we can tell that the surface of substrate become really coarse and rough.

To get a clearer picture of the density of these three samples, we calculated the number of CNTs from various parts of chips in different runs of CNT growth, and get three average $\mathrm{CNT}$ densities with three $\mathrm{Cu}$ underlayer thicknesses, which are shown in the Fig. 7. This figure gives a clear view that the CNT density reaches the highest to $6.89 \times 10^{12} / \mathrm{m}^{2}$ with $20 \mathrm{~nm}$ thick $\mathrm{Cu}$ underlayer. While in the cases of $5 \mathrm{~nm}$ and $150 \mathrm{~nm}$ thick $\mathrm{Cu}$ underlayer, the density is almost the same to be around $4 \times 10^{12} / \mathrm{m}^{2}$.

We suspected that it's because the thickness of $\mathrm{Cu}$ underlayer alters the surface roughness, and finally leads to different CNT density. Diffusions between contiguous metal layers during $\mathrm{CNT}$ growth at high temperature are inevitable as reported before. Diffusions between different layers in CNT growth were also reported before [19]. We suspect that this phenomenon is caused by the diffusion of $\mathrm{Cu}$ into $\mathrm{Al}_{2} \mathrm{O}_{3}$ barrier layer. When there is only limited amount of $5 \mathrm{~nm}$ thick $\mathrm{Cu}$ underlayer, the effect of diffusion is not so obvious. Whereas, increasing $\mathrm{Cu}$ underlayer to $150 \mathrm{~nm}$ may lead to too much diffusion which may poison the Ni catalyst thus less dense CNT growth. As our set of experiment shows, $\mathrm{Cu}$ underlayer of $20 \mathrm{~nm}$ thick may be most suitable and favorable for dense CNT growth.

\section{Conclusions}

In order to integrate CNTs into NEMS applications, we still need to research into more detailed fundamental studies on CNT growth, such as the effects of substrates and underlayers. The first part of this paper showed the effects of substrates on CNT growth, by changing the substrate from $\mathrm{Si}$ to HR Si and increasing the thickness of $\mathrm{SiO}_{2}$ on the surface. In addition, we obtained a reasonable result by adding a TiW layer on $\mathrm{HR} \mathrm{Si/thick} \mathrm{SiO}_{2}$ substrate. Then we also verified the thickness of $\mathrm{Cu}$ underlayer does affect CNT growth density.

Acknowledgments This work was supported by EU programs "Nanotec", "Mercure", "Nanocom", "Nano-RF" and "Nanotherm", the SSF program "Scalable Nanomaterials and Solution Processable Thermoelectric Generators", and also Contract No. EM11-0002. This work was also carried out as a part of the Sustainable Production Initiative and the Production Area of Advance at Chalmers. In addition, the work was also supported by the Shanghai Science and Technology Program (Grant No. 12JC1403900) and NSFC (Grant No. 51272153).

\section{References}

1. Che J, Çagin T, Goddard WA (2000) Thermal conductivity of carbon nanotubes. Nanotechnology 11(2):65-69

2. Huxtable ST, Cahill DG, Shenogin S, Xue L, Ozisik R, Barone P, Usrey M, Strano MS, Siddons G, Shim M, Keblinski P (2003) Interfacial heat flow in carbon nanotube suspensions. Nat Mater 2(11):731-734 
3. Allaoui A, Bai S, Cheng H, Bai J (2002) Mechanical and electrical properties of a MWNT/epoxy composite. Compos Sci Technol 62(15):1993-1998

4. Salvetat JP, Bonard JM, Thomson NH, Kulik AJ, Forró L, Benoit W, Zuppiroli L (1999) Mechanical properties of carbon nanotubes. Appl Phys A 69(3):255-260

5. McEuen PL, Fuhrer MS, Park H (2002) Single-walled carbon nanotube electronics. IEEE Trans Nanotechnol 1(1):78-85

6. Lau AKT, Hui D (2002) The revolutionary creation of new advanced materials - carbon nanotube composites. Compos Part B: Eng 33(4):263-277

7. Thostenson ET, Ren Z, Chou TW (2001) Advances in the science and technology of carbon nanotubes and their composites: a review. Compos Sci Technol 61(13):1899-1912

8. Bohr MT (2002) Nanotechnology goals and challenges for electronic applications. IEEE Trans Nanotechnol 1(1):56-62

9. Jang JE, Cha SN, Choi YJ, Kang DJ, Butler TP, Hasko DG, Jung JE, Kim JM, Amaratunga GAJ (2008) Nanoscale memory cell based on a nanoelectromechanical switched capacitor. Nat Nanotechnol 3(1):26-30

10. Huczko A (2000) Template-based synthesis of nanomaterials. Appl Phys A 70(4):365-376

11. Jiang D, Wang T, Chen S, Ye L, Liu J (2013) Paper-mediated controlled densification and low temperature transfer of carbon nanotube forests for electronic interconnect application. Microelectron Eng 103:177-180

12. Fu Y, Nabiollahi N, Wang T, Wang S, Hu Z, Carlberg B, Zhang Y, Wang X, Liu J (2012) A complete carbon-nanotube-based onchip cooling solution with very high heat dissipation capacity. Nanotechnology 23(4):045304
13. Huang ZP, Wang DZ, Wen JG, Sennett M, Gibson H, Ren ZF (2002) Effect of nickel, iron and cobalt on growth of aligned carbon nanotubes. Appl Phys A 74(3):387-391

14. Kim SM, Gangloff L (2011) Thermal chemical vapor deposition (T-CVD) growth of carbon nanotubes on different metallic underlayers. Phys E: Low-Dimens Syst Nanostruct 43(8):14811485

15. Hu JL, Yang CC, Huang JH (2008) Vertically-aligned carbon nanotubes prepared by water-assisted chemical vapor deposition. Diam Relat Mater 17(12):2084-2088

16. Ziaei A, Charles M, Le Baillif M, Xavier S, Caillard A, Cojocaru Cs (2010) Capacitive and ohmic RF NEMS switches based on vertical carbon nanotubes. Int J Microw Wirel Technol 2(5): 433-440

17. Feng Z, Lueck MR, Temple DS, Steer MB (2012) High-performance solenoidal RF transformers on high-resistivity silicon substrates for 3D integrated circuits. IEEE Trans Microw Theory Tech 60(7):2066-2072

18. Zhang F, Shi L, Li C (2005) Cpw transmission insertion loss on Si and Soi substrates. Microw J 48(11):138-142

19. Teo KBK, Chhowalla M, Amaratunga GAJ, Milne WI, Legagneux P, Pirio G, Gangloff L, Pribat D, Semet V, Binh VT, Bruenger WH, Eichholz J, Hanssen H, Friedrich D, Lee SB, Hasko DG, Ahmed H (2003) Fabrication and electrical characteristics of carbon nanotube-based microcathodes for use in a parallel electron-beam lithography system. J Vac Sci Technol B: Microelectron Nanometer Struct 21(2):693-697 